\title{
RETENÇÃO DE ÁGUA EM UM LATOSSOLO EM RECUPERAÇÃO COM ADUBOS VERDES ${ }^{1}$
}

\author{
Carolina dos Santos Batista Bonini ${ }^{2}$
}

Alfredo Bonini Neto ${ }^{3}$

Reges Heinrichs; ${ }^{4}$

Cecílio Viega Soares Filho ${ }^{5}$

\begin{abstract}
RESUMO
A degradação dos solos é caracterizada pela mudança na qualidade da estrutura, provocando diminuição no tamanho dos poros, especialmente dos macroporos, o que leva à redução na área da seção transversal para o fluxo de água. Com isso, o objetivo deste trabalho foi avaliar a retenção de agua de um Latossolo em recuperação com adubos verdes. O delineamento experimental foi inteiramente casualizados, com 9 tratamentos e 4 repetições. Os tratamentos foram: Testemunha (solo mobilizado); Mucuna-preta (Stizolobiumaterrimum Piper \& Tracy); Guandu (CajanuscajanL. Millsp), até 1994, após substituído por Feijão-de-porco (Canavalia ensiformes L);Calcário+Mucunapreta; Calcário+Guandu até 1994, após substituído por Feijão-de-porco; Calcário+Gesso+Mucunapreta;Calcário+Gesso+Guandu, até 1994, após substituído por Feijão-de-porco, duas Testemunhas T1 - Solo exposto (sem técnica de recuperação) e T2 - Vegetação nativa de Cerrado. Todos os tratamentos de recuperação após 1999 foram conduzidos com Brachiaria decumbens.Foi realizada coleta de solo (amostras indeformadas), nas camadas de 0,00-0,10; 0,10-0,20 e 0,20-0,40m para a determinação da retenção de água no solo, no ano de 2010. Os tratamentos de recuperação não influenciaram a retenção de agua no solo. A vegetação nativa do cerrado obteve menor valor, devido a melhor distribuição de tamanho de poros. Observou que quanto maior a retenção de água, maior a microporosidade do solo.Conclui-se que o solo ainda não está recuperado avaliando a retenção de agua no solo.Na camada superficial do solo, a retenção de agua é menor do que nas camadas mais profundas.
\end{abstract}

PALAVRAS-CHAVE:porosidade do solo. área degradada. Matéria orgânica.

\footnotetext{
${ }^{1}$ Projeto Financiado pela FAPESP

${ }^{2}$ UNESP -Universidade Estadual Paulista “Júlio de Mesquita Filho - carolbonini@dracena.unesp.br

${ }^{3}$ UNESP -Universidade Estadual Paulista "Júlio de Mesquita Filho

${ }^{4}$ UNESP _Universidade Estadual Paulista "Júlio de Mesquita Filho

${ }^{5}$ UNESP -Universidade Estadual Paulista "Júlio de Mesquita Filho
} 


\section{INTRODUÇÃO}

A compactação é um dos problemas mais agravantes das áreas degradadas, influenciando no crescimento das espécies vegetais e na capacidade da fauna do solo sobreviver nestas áreas que se tornam inabitáveis. Sendo assim, uma das primeiras medidas físicas a serem aplicadas nestas áreas degradadas são relacionadas à diminuição da densidade do solo, seja por meio de manejo com máquinas pesadas ou da aplicação de matéria orgânica (KITAMURA, 2007).

Quando ocorre a degradação da estrutura do solo, há modificações no arranjamento de suas partículas, provocando diminuição no tamanho dos poros, especialmente daqueles de tamanho maior (macroporos), o que leva à redução na área da seção transversal para o fluxo de água, juntamente com percursos mais tortuosos para o movimento de fluido, afetando com isso o processo de infiltração (SOUZA; ALVES, 2003).

TEIXEIRA ET AL. (1997) relataram que os efeitos das plantas podem resultar em alterações nas características químicas e propriedades físico-hídricas do solo. Como por exemplo, as alterações que algumas plantas provocam na macroporosidade, devido aos canais abertos pelas raízes. O volume e a distribuição do espaço poroso são muito importantes, visto que são nesses espaços que se processam os principais fenômenos que regulam o crescimento e a produção vegetal, tais como: reações químicas e biológicas, difusão de gases e íons, movimento e retenção de água e penetração de raízes.

A presença de agregados estáveis potencializa a capacidade de armazenamento de água, diminuindo as perdas de partículas e nutrientes por processos erosivos e facilita a proteção física e o acúmulo de matéria orgânica no solo (JASTROW et al., 1998).

Vários trabalhos têm sido desenvolvidos para avaliar o efeito da adição de matéria orgânica. ANDRADE JUNIOR (2004) trabalhou em área degradada com objetivo de estudar o efeito de adubo verde, calcário e gesso e verificou que os tratamentos de recuperação empregados agiram de forma semelhante na recuperação das propriedades físicas. ALVES E SUZUKI (2004) observaram que o 
uso de plantas de cobertura aliado à sucessão de culturas (milho e soja) sob semeadura direta melhorou as propriedades físicas do solo, como porosidade, densidade do solo e resistência do solo à penetração. E SILVA ET AL. (2002) em estudo realizado na "área de empréstimo" originada da construção da usina hidroelétrica de Ilha Solteira - SP, com o objetivo de verificar os efeitos de espécies e variedades de pinus, instaladas em 1982, na recuperação do solo, verificou que: 0 Pinus caribaeavar.hondurensis mostrou-se promissor, por apresentar um bom crescimento aliado a sua sobrevivência; as características físicas do solo (macroporosidade, microporosidade, porosidade total e densidade do solo), que não apresentaram diferenças entre os tratamentos.

A infiltração do solo é um dos fenômenos que melhor refletem as condições físicas internas do solo, pois uma boa qualidade estrutural leva a uma distribuição de tamanho de poros favorável ao crescimento de raízes e à capacidade de infiltração de água no solo (ALVES; CABEDA, 1999). E considerada por DORAN E PARKIN (1994), como uma das propriedades físicas utilizadas como indicadores básicos na avaliação da qualidade do solo.

O tamanho dos poros influencia na movimentação e na retenção de água no solo, quanto menor for a porosidade total de um solo maior será o escoamento superficial e a erosão. As práticas de manejo do solo exercem influência em sua estrutura e, consequentemente, em sua porosidade. CECONI ET AL. (2007) e MATIAS ET AL. (2009) verificaram uma diferença entre a porosidade total em solos sob diferentes sistemas de uso e manejo, observando uma menor porosidade em solos com uso mais intensivo.

\section{OBJETIVOS}

Mediante a preocupação de equacionar os problemas que envolvem a recuperação do solo e compreender os fatores que estão associados a resiliência da área estudada, este trabalho tem por objetivo avaliar a retenção de agua no solo de um solo decapitado que está sob intervenção antrópica com técnicas para recuperação há 17 anos, tendo sido utilizado adubos verdes, correção do solo, gesso e pastagem. 


\section{METODOLOGIA}

O experimento foi conduzido na Fazenda de Ensino, Pesquisa e Extensão, pertencente à Faculdade de Engenharia, Campus de Ilha Solteira, da Universidade Estadual Paulista (UNESP), no município de Selvíria, MS. A mesma está localizada na margem direita do Rio Paraná, apresentando as coordenadas geográficas de 510 22' de longitude oeste de Greenwich e 200 22' de latitude sul, com altitude de 327 metros. Apresenta médias anuais de precipitação, temperatura e umidade relativa do ar de: 1370 mm, 23,50 C e 70-80 \%, respectivamente (DEMATTÊ, 1980).

O solo da área de estudo foi classificado com Latossolo Vermelho-Escuro distrófico (DEMATTÊ, 1980), textura franco argilo-arenosa (KITAMURA, 2007), muito profundo, rico em sesquióxidos. A sua fração argila é de baixa atividade e denominada essencialmente pela gibsita e caulinita. Pela nomenclatura atual no nível de grande grupo é um Latossolo Vermelho distrófico (EMBRAPA, 2013).

A usina Hidrelétrica de llha Solteira, SP teve o início de sua construção na década de 60 , sendo que da área em estudo foi retirado solo para a terraplanagem e fundação da barragem, dando origem a uma área degradada, a qual é denominada de "área de empréstimo". Foi removida uma camada de 8,6 metros do perfil do solo original, sendo que o subsolo da área em estudo estava exposto desde 1969 (ALVES; SOUZA, 2008).

No ano de 1992, o subsolo apresentava-se com compactação superficial e baixa presença de vegetação espontânea. Nesse mesmo ano iniciou-se o trabalho de recuperação, e o solo foi preparado efetuando-se uma subsolagem atingindo profundidade média de 0,40 m. Foi efetuada também, uma aração e após essa operação, uma gradagem niveladora. A caracterização físico-química da área foi realizada no momento da instalação do experimento (Tabelas 1 e 2).

A correção do solo foi baseada na caracterização química da área experimental. A aplicação de calcário para elevar a saturação por bases a $70 \%$, foi efetuada, empregando-se a quantidade de $18,5 \mathrm{~kg}$ de calcário por parcela (1850 kg de calcário por ha) nas parcelas com calcário somente e, no caso das parcelas com calcário e gesso, houve a substituição de $25 \%$ de $\mathrm{CaO}$ do calcário por $25 \%$ do 
gesso, aplicando-se 5,2 kg de gesso (520 kg de gesso por ha) e 13,8 kg de calcário por parcela (1380 kg de calcário por ha), ambos incorporados no solo. Foi utilizado calcário dolomítico com PRNT de $70 \%$.

Foram semeadas em dezembro-janeiro dos anos de 1992 a 1996 espécies de adubos verdes (mucuna-preta, guandu, aveia-preta e feijão-de-porco), a semeadura das espécies foi realizada manualmente e, a densidade de semeadura dos adubos verdes foi de 10 plantas por metro linear, com o intuito de melhorar as características físicas e químicas do subsolo em estudo e, no inicio do florescimento foram roçadas e deixadas na superfície.

Tabela 1 -Propriedades químicas do subsolo exposto, realizada antes da implantação do experimento (1992).

\begin{tabular}{|c|c|c|c|c|c|c|c|c|c|c|}
\hline Camada. & $P_{\text {resina }}$ & M.O. & $\mathrm{pH}$ & K & $\mathrm{Ca}$ & $\mathrm{Mg}$ & $\mathrm{H}+\mathrm{Al}$ & SB & CTC & V\% \\
\hline (m) & $\mathrm{mg} \mathrm{dm}^{-3}$ & $\mathrm{~g} \mathrm{dm}^{-3}$ & $\mathrm{CaCl}_{2}$ & \multicolumn{7}{|c|}{$\mathrm{mmol}_{\mathrm{C}} \mathrm{dm}^{-3}$} \\
\hline $0,00-0,20$ & 1 & 7,0 & 4,0 & 0,2 & 2,0 & 1,0 & 20,0 & 3,2 & 23,2 & 14 \\
\hline $0,20-0,40$ & 0 & 4,0 & 4,2 & 0,2 & 2,0 & 1,0 & 20,0 & 3,2 & 23,2 & 14 \\
\hline
\end{tabular}

Fonte: Alves (2001)

Tabela2 - Propriedades físicas (macroporosidade, microporosidade, porosidade total e densidade do solo) do subsolo exposto, realizada antes da implantação do experimento (1992).

\begin{tabular}{|c|c|c|c|c|}
\hline $\begin{array}{l}\text { Camada. } \\
\mathrm{m}\end{array}$ & Macroporosidade & $\begin{array}{l}\text { Microporosidade } \\
-\mathrm{m}^{3} \mathrm{~m}^{-3}\end{array}$ & Porosidade Total & $\begin{array}{c}\text { Densidade do solo } \\
\mathrm{kgdm}^{-3}\end{array}$ \\
\hline $0,00-0,10$ & 0,10 & 0,25 & 0,35 & 1,52 \\
\hline $0,10-0,20$ & 0,08 & 0,25 & 0,33 & 1,69 \\
\hline $0,20-0,40$ & 0,07 & 0,26 & 0,33 & 1,74 \\
\hline
\end{tabular}

Fonte: Alves (2001)

Em 1996 foi realizada novamente a correção do solo, com base na análise química, para os tratamentos com calcário e calcário mais gesso. A substituição de $\mathrm{CaO}$ do calcário pelo $\mathrm{CaO}$ do gesso seguiu o mesmo procedimento do inicio do experimento. A correção foi efetuada nos casos em que a saturação por bases estava inferior a $60 \%$, objetivando-se elevá-la a $70 \%$.

Em janeiro de 1997, foi semeada em toda a área experimental a cultura do milho (Zeamays L.) utilizando a semente do híbrido AG 405 e $250 \mathrm{~kg} \mathrm{ha}^{-1}$ da fórmula 4-30-10 mais 0,3\% de zinco, sem aplicação de calcário; porém, sem muito sucesso, pois as plantas apresentaram pouco crescimento e obteve-se baixo rendimento de grãos, com espigas de 0,10 m de comprimento. Em junho de 1998, foi semeada a 
aveia-preta (Avena strigosaSchieb.), houve boa germinação, porém, por falta de água, a cultura não resistiu e, com poucos centímetros de altura morreu. Em fevereiro de 1999, foi semeada a BrachiariadecumbensStapf., com o intuito de proteger o solo e acumular matéria orgânica ao mesmo. Em 2006, avaliou-se a presença espontânea de espécies arbóreas nativas de cerrado.

O delineamento experimental utilizado foi inteiramente casualizado, constando de nove tratamentos e quatro repetições. A dimensão de cada parcela foi de $10 \mathrm{~m} \times 10 \mathrm{~m}$. Os tratamentos foram:

1 - SM/B: Solo mobilizado e ocorrência de vegetação espontânea, até 1999, após implantada Brachiaria decumbens;

2 -MP/B: Mucuna-preta (Stizolobiumaterrimum Piper e Tracy) até 1999 após substituída por $B$. decumbens;

3 - G/FP/B: Guandu (Cajanuscajan (L.) Millsp), até 1994, após substituído por Feijão-de-porco e a partir de 1999 substituído por B. decumbens;

4 -C+MP/B:Calcário + Mucuna-preta até 1999, após substituída por B. decumbens;

5 -C+G/FP/B:Calcário + Guandu até 1994, após substituído por Feijão-de-porco e a partir de 1999 substituído por $B$. decumbens;

$6-$ C+Ge+MP/B: Calcário + Gesso + Mucuna-preta até 1999 após substituída por B. decumbens;

7 -C+Ge+G/FP/B:Calcário + Gesso + Guandu, até 1994, após substituído por Feijãode-porco e a partir de 1999 substituido por $B$. decumbens e, duas Testemunhas:

8 - SE: Subsolo exposto (sem técnica de recuperação) e

9 - MA: Vegetação nativa de Cerrado.

No ano de 2010, avaliou-se a retenção de água, sendo que para a tensão mais baixa, isto é, $6 \mathrm{kPa}$ foi empregada na mesa de tensão, segundo KIEHL (1979) e, para as tensões de 50, 100 e $200 \mathrm{kPa}$, foi utilizada a câmara de Richards, seguindo-se a metodologia de RICHARDS (1965). Foram coletadas amostras indeformadas de solo, com anel volumétrico as comparações de média no nível de 5 $\%$ de probabilidade. Foi usado o programa computacional SISVAR (FERREIRA, 2008), para a realização da análise estatística. 


\section{RESULTADOS E DISCUSSÃO}

Para a retenção de água no solo, nas camadas de 0,00-0,10; 0,10-0,20 e 0,20-0,40 m, os valores médios encontram-se nos Tabela3, para os anos de 2010, respectivamente. Houve diferença significativa para todas as camadas de solo, tensões.

Para a retenção de água no solo, na tensão de - $50 \mathrm{kPa}$, nas camadas de solo estudas, os menores valores encontrados foi para a testemunha vegetação nativa do cerrado, os maiores valores para os tratamentos de recuperação, Para as outras tensões estudadas $(-100 \mathrm{kPa}$ e $-200 \mathrm{kPa})$ foi observado o mesmo comportamento.

Nota-se que quanto maior os valores de retenção de água no solo, maior microporosidade deste solo, com isso o solo exposto que é um solo degradado e os solos dos tratamentos que ainda estão em processo de recuperação, apresentaram maior retenção de água.

Para os tratamentos de recuperação, os resultados obtidos foram iguais para todos os tratamentos utilizados, isso deve ao uso da braquiária em toda área experimental deste o ano de 1999. O uso da braquiária tem sido eficiente na restauração do solo, porque além de cobrir o solo e diminuir os efeitos da agua da chuva, as raízes dessa gramínea fornece matéria orgânica para o solo, que são fonte de agentes cimentantes para a estruturação do solo e consequentemente a distribuição do tamanho de poros.

O solo da vegetação nativa do cerrado, apresentou menor retenção de água no solo e segundo Figueiredo et al, (2008), os Latossolos do cerrado são solos que apresentam baixa retenção de água, devido principalmente, à composição oxídica da fração argila e a presença de estrutura do tipo granular.

Os resultados encontrados neste estudo estão de acordo com Costa (2010), que estudou diversos tipos de solo e manejos, na região de llha Solteira e constatou valores semelhantes para o Latossolo Vermelho distrófico. 
Tabela 3 - Valores médios para a retenção de água no solo (-50, -100 e -200 kPa ), teste F e coeficiente de variação (CV\%), nas camadas de solo estudadas, Selvíria, MS, 2010.

\begin{tabular}{|c|c|c|c|}
\hline Tratamentos & $0,00-0,10 \mathrm{~m}$ & $\begin{array}{l}-50 \mathrm{kPa} \\
0,10-0,20 \mathrm{~m}\end{array}$ & $0,20-0,40 \mathrm{~m}$ \\
\hline SM/B & $0,19 a$ & $0,21 a$ & $0,23 a$ \\
\hline MP/B & $0,20 a$ & $0,21 a$ & $0,24 a$ \\
\hline G/FP/B & $0,20 a$ & $0,21 \mathrm{a}$ & $0,24 a$ \\
\hline $\mathrm{C}+\mathrm{MP} / \mathrm{B}$ & $0,20 \mathrm{a}$ & $0,21 a$ & $0,23 a$ \\
\hline C+G/FP/B & $0,20 a$ & $0,22 \mathrm{a}$ & $0,24 a$ \\
\hline $\mathrm{C}+\mathrm{GE}+\mathrm{MP} / \mathrm{B}$ & $0,20 a$ & $0,20 a$ & $0,24 a$ \\
\hline $\mathrm{C}+\mathrm{GE}+\mathrm{G} / \mathrm{FP} / \mathrm{B}$ & $0,20 a$ & $0,21 a$ & $0,22 a$ \\
\hline MA & 0,13 & $0,12 \quad c$ & 0,12 \\
\hline SE & $0,18 \mathrm{~b}$ & $0,18 \quad b$ & $0,20 \mathrm{~b}$ \\
\hline $\mathrm{F}$ & 27,746 * & $52,585^{*}$ & $59,304^{*}$ \\
\hline \multirow[t]{3}{*}{ CV } & 8,92 & 7,84 & 7,99 \\
\hline & \multicolumn{3}{|c|}{$-100 \mathrm{kPa}$} \\
\hline & $0,00-0,10 \mathrm{~m}$ & $0,10-0,20 \mathrm{~m}$ & $0,20-0,40 m$ \\
\hline SM/B & $0,18 \mathrm{a}$ & $0,20 a$ & $0,23 a$ \\
\hline $\mathrm{MP} / \mathrm{B}$ & $0,19 a$ & $0,21 a$ & $0,23 a$ \\
\hline G/FP/B & $0,19 a$ & $0,20 a$ & $0,23 a$ \\
\hline $\mathrm{C}+\mathrm{MP} / \mathrm{B}$ & $0,18 a$ & $0,20 a$ & $0,23 a$ \\
\hline $\mathrm{C}+\mathrm{G} / \mathrm{FP} / \mathrm{B}$ & $0,19 a$ & $0,21 \mathrm{a}$ & $0,23 a$ \\
\hline C+GE+MP/B & $0,18 a$ & $0,19 a$ & $0,23 a$ \\
\hline $\mathrm{C}+\mathrm{GE}+\mathrm{G} / \mathrm{FP} / \mathrm{B}$ & $0,18 a$ & $0,20 a$ & $0,21 \mathrm{~b}$ \\
\hline MA & 0,11 & 0,11 & 0,12 \\
\hline SE & $0,17 \quad b$ & 0,17 & 0,19 \\
\hline $\mathrm{F}$ & $31,227^{*}$ & $52,317^{*}$ & $56,399^{*}$ \\
\hline \multirow[t]{3}{*}{ CV } & 8,81 & 8,17 & 8,28 \\
\hline & \multicolumn{3}{|c|}{$-200 \mathrm{kPa}$} \\
\hline & $0,00-0,10 m$ & $0,10-0,20 m$ & $0,20-0,40 m$ \\
\hline SM/B & $0,17 a$ & $0,18 b$ & 0,20-0,40m \\
\hline MP/B & $0,18 \mathrm{a}$ & $0,20 a$ & $0,22 a$ \\
\hline $\mathrm{G} / F P / B$ & $0,18 a$ & $0,19 a$ & $0,22 a$ \\
\hline $\mathrm{C}+\mathrm{MP} / \mathrm{B}$ & $0,17 a$ & $0,18 b$ & $0,21 a$ \\
\hline $\mathrm{C}+\mathrm{G} / \mathrm{FP} / \mathrm{B}$ & $0,18 a$ & $0,20 a$ & $0,22 \mathrm{a}$ \\
\hline C+GE+MP/B & $0,18 a$ & $0,18 b$ & $0,22 a$ \\
\hline $\mathrm{C}+\mathrm{GE}+\mathrm{G} / \mathrm{FP} / \mathrm{B}$ & $0,18 a$ & $0,19 a$ & $0,20 \mathrm{~b}$ \\
\hline MA & $0,11 b$ & 0,10 & 0,11 \\
\hline SE & $0,16 \mathrm{a}$ & $0,17 \mathrm{~b}$ & $0,19 \quad c$ \\
\hline $\mathrm{F}$ & $23,277^{*}$ & $24,284^{*}$ & $46,122^{*}$ \\
\hline CV & 9,83 & 11,86 & 8,97 \\
\hline
\end{tabular}

Médias seguidas de letras iguais na coluna não diferem entre si pelo teste de Scott-Knott a $5 \%$ de probabilidade, SM/B = Solo mobilizado até 1999, após implantada Braquiária; MP/B = Mucuna-preta até 1999 após substituída porBraquiária; G/FP/B = Guandu até 1994, após substituído por Feijão-deporco e a partir de 1999 substituído por Braquiária; C+MP/B = Calcário + Mucuna-preta até 1999, após substituída por Braquiária; $\mathrm{C}+\mathrm{G} / \mathrm{FP} / \mathrm{B}=$ Calcário+Guandu até 1994, após substituído por Feijãode-porco e a partir de 1999 substituído por Braquiária; $\mathrm{C}+\mathrm{Ge}+\mathrm{MP} / \mathrm{B}=$ Calcário+Gesso+Mucuna-preta até 1999 após substituída por Braquiária;C+Ge+G/FP/B=Calcário+Gesso Guandu, até 1994, após substituído por Feijão-de-porco e a partir de 1999 substituído por Braquiária; MA = Vegetação nativa do Cerrado; SE = Solo Exposto. Fonte: dados do próprio autor. 


\section{CONCLUSÃO}

A retenção de agua no solo, nos tratamentos utilizados indicam que o solo estudado ainda está degradado. Quanto maior a retenção de água, maior a microporosidade do solo.

$\mathrm{Na}$ camada superficial do solo, a retenção de agua é menor do que nas camadas mais profundas.

\section{Referencias}

ALVES, Marlene Cristina; SUZUKI, Luiz Eduardo A. SanchesInfluência de diferentes sistemas de manejo do solo na recuperação de suas propriedades físicas. Acta ScientiarumAgronomy, Maringá, v. 26, n. 1, p. 27-34, 2004.

ALVES, Marlene Cristina; CABEDA, Mario Sergio VazInfiltração de água em um Podzólico Vermelho-Escuro sob dois métodos de preparo, usando chuva simulada com duas intensidades. Revista Brasileira de Ciência do Solo, Campinas, v. 23, p. 753-761, 1999.

ALVES, Marlene Cristina; SOUZA, Zigomar MenezesRecuperação de área degradada por construção de hidroelétrica com adubação verde e corretivo. Revista Brasileira de Ciência do Solo, Campinas, v. 32, p. 2505-2516, 2008.

ANDRADE JÚNIOR, Roberto TeixeraPropriedades físico-químicas de um solo em recuperação e adaptação da Brachiaria decumbens. 2004. 49 f. Trabalho de Conclusão de Curso. Graduação (Graduação em Agronomia) - Faculdade de Engenharia, Universidade Estadual Paulista, Ilha Solteira, 2004.

CECONI, Denise Ester et al. Influência do uso do solo nas propriedades físicas na microbacia hidrográfica do Lageado Biguá, Alecrim-RS. In: CONGRESSO BRASILEIRO DE CIÊNCIA DO SOLO, 31, 2007, Gramado. Anais... Gramado: Sociedade Brasileira de Ciência do Solo, 2007. CDROM.

COSTA, CarlaDeisiene OliveiraEscoamento superficial e risco de erosão do solo na sub-bacia Jardim Novo Horizonte, Município de llha Solteira-SP. 2010. v, 88 f. Dissertação (mestrado) Universidade Estadual Paulista, Faculdade de Ciências Agronômicas de Botucatu, 2010.

DEMATTÊ, José Luiz loratteLevantamento detalhado dos solos do Campus Experimental de llha Solteira (SP).Piracicaba, 1980. 131 p. (Mimeogr.).

DORAN, J. W.; PARKIN, T.B. Defining and assessing soil quality.In: DORAN, J. W.; COLEMAN, D. C.; BEZDICEK, D. F. ; STEWART, B. A. (Ed.). Defining soil quality for a sustainable environment. Madison: ASA, CCSA, SSSA, 1994. p. 3-21.(SSSA Spec. Publ., 35).

EMBRAPA. Centro Nacional de Pesquisa de Solos. Sistema Brasileiro de Classificação de Solos. 3aㅡ ed. Brasília, DF : Embrapa, 2013. 353p.

FERREIRA, Daniel FurtadoSISVAR: um programa para análises e ensino de estatística. Revista Symposium, 6: 36-41, 2008. 
FIGUEIREDO, Cícero Célio et alPropriedades físicas e matéria orgânica de um Latossolo Vermelho sob sistemas de manejo e cerrado nativo.Bioscience, Uberlândia, v. 24, n. 3, p. 24-30, 2008.

JASTROW, Julie D. et al.Contributions of interacting biological mechanisms to soil aggregate stabilization in restored prairie.Soil Biology and Biochemistry, Elmsford, v. 30, p. 905-916, 1998.

KIEHL, Edmar J. Manual de edafologia: relação solo-planta. São Paulo: Agronômica Ceres, 1979. $264 \mathrm{p}$.

Kitamura, AlineEmyRecuperação de um solo degradado com a aplicação de adubos verdes e lodo de esgoto. 2007. 117 f. Tese (Doutorado) - Faculdade de Engenharia, Universidade Estadual Paulista, Ilha Solteira, 2007.

MATIAS, Sammy Sidney Rochaet al. Atributos físicos de um Latossolo Vermelho submetido a diferentes usos. Revista Ciência Agronômica, Fortaleza, CE, v. 40, n. 3, p. 331-338, 2009.

RICHARDS, L. A. Physical conditions of water in soil. In: BLACK, C. A.; EVANS, D. D.; WHITE, J. L.; ENSMINGER, L. E.; CLARK, F. E. (Ed.). Methods of soil analysis: physical and mineralogical properties, including statistics of measurements and sampling.Madison: American SocietyofAgronomy, 1965. p. 128-152.

SILVA, Alexandre Marques et al Recuperação de áreas degradadas com a utilização de diferentes espécies e variedades de Pinus. Cultura Agronômica, llha Solteira, v. 11, n. 1, p. 1-11, 2002.

SOUZA, Zigomar Menezes; ALVES, Marlene Cristina Movimento de água e resistência à penetração em um Latossolo Vermelho distrófico de Cerrado, sob diferentes usos e manejos. Revista Brasileira de Engenharia Agrícola e Ambiental, Campina Grande, v.7, p. 18-23, 2003.

TEIXEIRA, Wenceslau G. et al. Avaliação de parâmetros físico-químicos e hídricos do solo como indicadores da recuperação de áreas degradadas na Amazônia Ocidental. In: SIMPÓSIO NACIONAL DE RECUPERAÇÃO DE AREAS DEGRADADAS, 3., 1997, Viçosa, MG. Anais... Viçosa: UFV, 1997. p. 166-174. 